\title{
AS DIMENSÕES CONCEITUAIS E NÃO CONCEITUAIS DA PRÁTICA BUDISTA-CENTRADO NO CAPÍTULO SOBRE AS TRÊS SABEDORIAS NO SATYA-SIDDHI-SÃSTRA.
}

\author{
Joaquim Antônio Bernardes Carneiro Monteiro ${ }^{1}$
}

\begin{abstract}
Resumo
O presente artigo se fundamenta integralmente na metodologia de análise textual conforme empregada na área dos estudos budistas e possui três objetivos básicos. O primeiro deles é discutir as dimensões conceituais e não conceituais da prática budista a partir do conceito das três sabedorias. O segundo é proporcionar um critério crítico para pensar a diferença entre a prática budista propriamente dita e as abordagens terapêuticas e científicas em relação à prática da meditação. O terceiro procura pensar a possibilidade de uma completa autonomia da dimensão conceitual da prática budista a partir de uma análise da relação entre as três sabedorias e os três mundos (do desejo, da forma e do informe) no Capítulo sobre as três sabedorias no Satya-siddhi-Sãstra.
\end{abstract}

Palavras-chave: dimensões conceituais e não conceituais da prática budista; três sabedorias; três mundos; absorção meditativa; Satya-siddhi-Sãstra.

\section{Introdução}

O objetivo central do presente artigo consiste em primeiro lugar em elucidar o problema das dimensões conceituais e não conceituais da prática budista. Ou seja, não se trata de pensar a dimensão conceitual como pertencendo à pura teoria e a dimensão não conceitual como pertencendo à prática, mas de elucidar um conceito de prática amplo o bastante para incluir em seu interior dimensões tanto conceituais como não conceituais. Este objetivo pode ser situado em sua relação com dois contextos de importância fundamental. O primeiro deles consiste na relação entre o conceito de prática no pensamento budista e os tópicos a ele relacionados na filosofia contemporânea. Supondo que a prática budista seja reduzida à sua dimensão não conceitual, ela se tornaria completamente irrelevante no diálogo com as questões da filosofia contemporânea. No entanto, caso a prática budista seja entendida em um contexto mais amplo capaz de incluir suas dimensões conceituais e não conceituais mesmo a dimensão não conceitual pode se tornar significativa no contexto do debate filosófico. $\mathrm{O}$ segundo deles diz respeito ao estabelecimento de critérios críticos capazes de distinguir

\footnotetext{
${ }^{1}$ Doutor em Filosofia Budista pela Universidade de Komazawa, Japão. Membro do GT-filosofia oriental da Anpof.
} 
claramente a prática budista propriamente dita das apropriações terapêuticas ou científicas da prática da meditação. Não se trata aqui de defender uma pura e simples condenação dos atuais desenvolvimentos científicos e terapêuticos da meditação através de uma suposta pureza da prática budista originária. (seja lá o que for que isto possa significar...), mas de estabelecer critérios críticos capazes de articular um diálogo entre o pensamento budista e as diversas modalidades de estudo científicas da meditação.

Esclarecido o acima, vamos procurar em seguida pensar os critérios que nos permitam elucidar a diferença entre essas dimensões conceituais e não conceituais da prática budista. Existem diversas possibilidades de pensar esta questão em meio à tradição budista, mas o conceito das três sabedorias do ouvir, da reflexão e do cultivo nos parece o mais promissor no contexto desta tarefa. Se as sabedorias do ouvir e da reflexão possuem um vínculo óbvio com as dimensões conceituais da prática, a sabedoria do cultivo parece apontar de forma bastante concreta para sua dimensão não conceitual. Evidentemente, existem nuances bastante complexas na forma como se estabelece a distinção entre essas modalidades de sabedoria, mas o seguinte trecho do Capítulo sobre as três sabedorias no Satya-siddhi-Sãstra pode contribuir de uma forma bastante concreta para elucidar o cerne desta questão:

\begin{abstract}
As três sabedorias consistem na sabedoria do ouvir, na sabedoria da reflexão e na sabedoria do cultivo. A sabedoria que surge a partir dos Sutras e das 12 divisões do ensinamento é chamada de sabedoria do ouvir. Como em função disto ela faz surgir a nobre sabedoria incontaminada é chamada de sabedoria. Conforme é ensinado nos Sutras, o BhikkuRãhula realiza agora a sabedoria da emancipação. Mesmo que se ouça os Sutras mundanos dos Vedas e semelhantes, como não é possível em função disto fazer surgir a sabedoria incontaminada isso não é chamado de sabedoria do ouvir. Caso ocorra a reflexão a respeito do sentido presente nos Sutras, isso é chamado de sabedoria da reflexão. Conforme é ensinado, o praticante ouve o dharma e reflete a respeito do seu sentido. Ou ainda se ensina, se o praticante tendo ouvido o dharma e refletido sobre o seu sentido praticar de acordo com ele, fazendo presente a compreensão e a visão, isto é chamado de sabedoria do cultivo. (TAISHOZÔ, 1924, p. 366)
\end{abstract}

Uma leitura atenta do trecho acima pode não ter dificuldade em elucidar a relação entre a dimensão conceitual da prática e as sabedorias do ouvir e da reflexão, mas a relação entre a dimensão não conceitual e a sabedoria do cultivo pode parecer bastante vaga. Assim sendo, se fazem necessárias algumas explicações no sentido de esclarecer essa relação. Em 
que pese a existência de uma diversidade de pontos de vista a respeito deste problema, o essencial desta questão pode ser esclarecido através dos pontos abaixo:

a. A dimensão conceitual presente nas sabedorias do ouvir e da reflexão pode ser entendida como a análise de categorias como os cinco agregados, as doze entradas e as dezoito esferas.

b. Caso a análise das dezoito esferas seja considerada o tópico central desta análise, elas consistem nas seis bases sensoriais (cinco órgãos dos sentidos e a função mental que capta os objetos não sensoriais), nos seis objetos (os objetos dos cinco sentidos e os objetos abstratos não sensoriais) e nas seis consciências que surgem da interação entre as bases e os objetos.

c. A análise das características não comuns das dezoito esferas implica na distinção entre o domínio de percepção de cada uma das seis consciências. É importante apontar aqui que se pressupõe uma multiplicidade de consciências com domínios de experiência claramente diferenciados.

d. A análise das características comuns das dezoito esferas implica na análise de sua impermanência, de sua insatisfatoriedade e do vazio de ãtman comum a todas elas.

e. A sabedoria do cultivo é geralmente associada às dimensões não conceituais como as quatro absorções meditativas do mundo da forma e as quatro absorções do mundo do informe. Essas absorções exigem um longo treinamento especializado em práticas como a consciência da entrada e da saída do ar no processo respiratório.

f. É possível concluir que apenas uma absorção meditativa que tenha por seu pano de fundo as sabedorias conceituais do ouvir e da reflexão possui a capacidade de realizar o caminho proposto pelo Budismo. Neste sentido, existe uma relação inseparável entre essas três sabedorias nas tendências dominantes da prática budista. Uma prática não conceitual não possui por si só o poder de realizar este caminho, mas as sabedorias conceituais só se completam através do cultivo da dimensão não conceitual.

Podemos pensar que a explicação acima seja suficiente no sentido de elucidar o sentido das três sabedorias e de sua relação com as dimensões conceituais e não conceituais da prática, mas existe ainda uma questão importante a ser elucidada no contexto dos objetivos 
do presente artigo. Ou seja, a relação entre essas duas dimensões da prática na passagem dos aspectos mundanos para os aspectos supramundanos do caminho. Esta questão pode ser devidamente situada através da seguinte citação do Capítulo sobre os estágios do caminho no AbhidharmaKosa de Vasubandhu: "Já foi devidamente explanada aqui que a desconexão das paixões se deve aos caminhos da visão e do cultivo. Na visão existe apenas o incontaminado, o cultivo possui duas modalidades" (TAISHOZÔ, 1924, p.113).

Explicando com algum detalhe o trecho acima, é possível dizer em primeiro lugar que existem dois aspectos no caminho, a saber, o caminho da visão e o caminho do cultivo. Como o caminho da visão se constitui por excelência no instante da passagem do mundano para o supramundano, ele é exclusivamente incontaminado. No entanto, no que diz respeito ao caminho do cultivo, existem duas modalidades, a saber, a modalidade mundana e a supramundana. O cultivo supramundano implica no conjunto de práticas que conduz o caminho à sua completitude, mas a importância do cultivo mundano é que ele se constitui na mediação que possibilita a passagem do mundano para o supramundano e a entrada no caminho da visão. No contexto tradicional esta dimensão implica em quatro fatores (o calor, a culminância, a paciência e os "Supremos dharmas mundanos"), mas vamos destacar aqui a importância dos "Supremos dharmas mundanos" como o momento decisivo desta passagem do mundano para o supramundano no contexto dos estágios do caminho. Na medida em que esses "Supremos dharmas mundanos" se constituem ao mesmo tempo como o último instante de consciência puramente mundana e como o instante precisamente anterior à entrada no caminho da visão (ou seja, do primeiro instante de consciência supramundana) eles se constituem na mediação central e indispensável à passagem acima mencionada. No entanto, existe neste contexto mais uma questão decisiva que precisa ser abordada. Ou seja, como definir a importância relativa dos papéis desempenhados pelas dimensões conceituais e não conceituais da prática no contexto desta passagem? Esse problema pode ser equacionado através dos pontos seguintes: a) neste contexto, o problema central se constitui na relação existente entre as três sabedorias e os assim chamados três mundos do desejo, da forma e do informe; b) o mundo do desejo pode ser definido como o domínio da experiência sensorial, o mundo da forma como o conteúdo da experiência não sensorial presente nas quatro absorções da forma e o mundo do informe como o universo da experiência vivencial nas quatro absorções do informe. Também é possível apresentar uma visão alternativa que define o 
mundo do desejo como a experiência de vigília, o mundo da forma como a experiência do sono com sonhos e o mundo do informe como o universo da experiência do sono sem sonhos; c) no contexto da prática do caminho budista, a dimensão conceitual presente nas sabedorias do ouvir e da reflexão é exercida centralmente no mundo do desejo e até certo ponto no mundo da forma, mas a sabedoria do cultivo exigiria em princípio algum nível de experiência do mundo da forma, não podendo se completar no mundo do desejo.

Esclarecidos os pontos acima, se torna possível formular com precisão a questão central do presente artigo: a realização dos "Supremos dharmas mundanos" e a passagem para o caminho da visão só poderia se dar exclusivamente através de uma conjunção entre as sabedorias do ouvir e da reflexão desenvolvidas de forma dominante no mundo do desejo e da entrada no mundo da forma através da primeira absorção meditativa ou poderia se dar de forma exclusivamente conceitual no contexto do mundo do desejo? Certamente, não é intenção do presente artigo proporcionar uma resposta conclusiva em relação a uma questão tão complexa, mas é possível apontar aqui para uma clara divergência entre o ponto de vista ortodoxo da escola Sarvãstivãda representado pelo 'Jnana-prasthãnae a perspectiva Sautrântica representada pelo Satya-siddhi-Sãstra. No Capitulo sobre os "Supremos dharmas mundanos" no Jnana-Prasthãna é colocado de forma inequívoca que a realização dos "Supremos dharmas mundanos" e a passagem para o caminho da visão só pode se dar no mundo da forma através da realização de pelo menos a primeira absorção meditativa (TAISHOZÔ, 1924). Em um claro contraste com este ponto de vista, o Capítulo sobre as três sabedorias do Satya-siddhi-Sãstra vai apontar concretamente para a realização dos "Supremos dharmas mundanos" e para a passagem para o caminho da visão através de uma forma completamente conceitual que se dá exclusivamente no mundo do desejo (TAISHOZÔ, 1924). É importante apontar aqui que esta abordagem não implica em uma pura e simples negação da sabedoria do cultivo, estando aqui implícito que mesmo o cultivo pode se concretizar através de uma via completamente conceitual. Na medida em que este ponto de vista é bastante atípico na história do pensamento budista e que ele talvez tenha o potencial de elucidar pontos de grande importância para o diálogo entre o pensamento budista e a filosofia contemporânea, ele será o objeto de análise na seção seguinte. 


\title{
Desenvolvimento
}

O objetivo central desta seção é discutir o tema da passagem dos estágios mundanos do caminho para os supramundanos conforme trabalhado no Capítulo sobre as três sabedorias no Satya-siddhi-Sãstra. Evidentemente, este tema será pensado na perspectiva da relação entre as três sabedorias e os três mundos conforme apontado na introdução deste mesmo artigo. No Capítulo sobre as três sabedorias este tópico é elucidado através de um diálogo entre o autor da obra e um suposto interlocutor. Este diálogo se inicia da seguinte forma:

\begin{abstract}
"Questão: quantas destas sabedorias pertencem ao mundo do desejo, quantas pertencem ao mundo da forma e quantas pertencem ao mundo do informe? Resposta: todas elas pertencem ao mundo do desejo e ao mundo da forma. Se um discípulo leigo renascer no mundo dos Devas sem paixões ele pode pregar o dharma nesta condição. Se uma pessoa pode pregar o dharma existe aí necessariamente a reflexão sobre o seu sentido. Em função disto, podemos saber que a sabedoria da reflexão ainda existe no mundo da forma. No mundo do informe existe apenas a sabedoria do cultivo.” (TAISHOZÔ, 1924, p. 367-A)
\end{abstract}

A questão central deste primeiro momento do diálogo consiste precisamente na relação entre as três sabedorias e os três mundos. A resposta parte do importante ponto de vista de que todas as três sabedorias estão presentes no mundo do desejo. Está implícita aí a possibilidade de uma realização completamente centrada na dimensão conceitual da prática e que se dá dentro dos estritos limites do mundo do desejo. O reconhecimento da presença das três sabedorias no mudo da forma também implica no reconhecimento da possibilidade de uma passagem dos "Supremos dharmas mundanos" para o caminho da visão através de uma combinação da dimensão conceitual com a entrada na primeira absorção meditativa. Este ponto de vista seria em princípio idêntico aquele defendido pela ortodoxia da escola Sarvãstivãda. Por fim, a restrição das três sabedorias à sabedoria do cultivo no mundo do informe nada possui de polêmico nem de problemático na medida em que se constitui quase em um consenso entre as diversas escolas do Abhidharma. O momento seguinte deste diálogo é como segue:

Questão: disse alguém que no mundo do desejo não existe a sabedoria do cultivo e que no mundo da forma não existe a sabedoria da reflexão. O que você pode dizer a este respeito?

Resposta: em função de que causas e condições não existe a sabedoria do cultivo no mundo do desejo? (TAISHOZÔ, 1924, p. 367-A). 
O diálogo acima coloca duas questões importantes no contexto da presente discussão. A negação da existência da sabedoria do cultivo no mundo do desejo implicaria na impossibilidade da plena realização do caminho no mudo do desejo através da dimensão conceitual da prática, a negação da presença da sabedoria da reflexão no mundo da forma implicaria por sua vez na impossibilidade da passagem dos "Supremos dharmas mundanos" para a entrada no caminho da visão no mundo da forma conforme proposto pela linha dominante da escola Sarvãstivãda. O autor interroga as razões por que este ponto de vista é proposto, mas é interessante que ele se limite a mencionar o mundo do desejo sem fazer referência alguma ao problema do mundo da forma. O terceiro momento deste diálogo é como segue:

Questão: no caminho do mundo do desejo não é possível extinguir as paixões. Essas desconexões (das paixões) não podem se fazer presentes no mundo do desejo.

Resposta: não existem essas palavras no dharma de Buddha. Pode-se falar que no caminho do mundo do desejo não ocorrem estas extinções ou que as desconexões não se fazem presentes. Mas ainda se ensina que é possível eliminar as paixões no mundo do desejo. Por que razão? Porque no mundo do desejo existem fatores como a contemplação da impureza. Conforme é ensinado nos Sutras é possível eliminar a cobiça através da contemplação da impureza. E é possível dizer o mesmo através de fatores como a compaixão (TAISHOZÔ, 1924, p. 367-A).

No desenvolvimento acima o suposto interlocutor afirma de forma bastante conclusiva que não é possível eliminar as paixões no mundo do desejo. Depois de afirmar que não existe esta asserção no dharma de Buddha, o autor considera algumas nuances desta questão e conclui defendendo a existência de fatores como a contemplação da impureza e a compaixão no mundo do desejo. Embora essas asserções do autor pareçam bastante fracas elas se direcionam para a defesa da realização do caminho no mundo do desejo. O quarto momento deste diálogo é como segue:

Questão: não é possível eliminar as paixões de forma definitiva através de fatores como a contemplação da impureza no mundo do desejo.

Resposta: também não é possível eliminar as paixões de forma definitiva através da contemplação da impureza no mundo da forma. Ou ainda, também não é possível a suprema desconexão das paixões (TAISHOZÔ, 1924, p. 367-A, B). 
No desenvolvimento acima, o interlocutor nega o caráter definitivo da extinção das paixões devida a fatores como a contemplação da impureza no mundo do desejo. O autor se limita a responder que este também é o caso a respeito da contemplação da impureza no mundo da forma. Essa resposta pode parecer bastante vaga, mas está implícito aí o propósito de defender a validade do cultivo no mundo do desejo. O quinto momento desta interlocução é como segue:

\begin{abstract}
Questão: é através de atividades mais sutis que é possível extinguir as paixões e não através da contemplação da impureza.

Resposta: nos Sutras não se ensina que é possível extinguir as paixões através de atividades mais sutis e não através da contemplação da impureza. É ensinado nos Sutras: é possível eliminar as paixões através da contemplação da impureza.

$\mathrm{Ou}$ ainda, que poderes misteriosos possuem essas atividades mais sutis para poderem extinguir as paixões que a contemplação da impureza não possua? $\mathrm{Ou}$ ainda, se existirem essas atividades sutis no mundo do desejo, deve ser possível extinguir as paixões através delas. Caso isso não seja possível se torna necessário explicar as razões. Por que razão? Porque aonde existem as impurezas não existem as atividades mais sutis. Supondo que existam elas não devem ser capazes de extinguir as paixões. Mesmo que elas existam no mundo da forma elas não devem possuir essa capacidade. Ainda se torna preciso explicar as razões disto. Por que razão isto seria possível no mundo da forma e não no mundo do desejo? (TAISHOZÔ, 1924, p. 367-B).
\end{abstract}

A discussão acima aparenta possuir um caráter bastante formal e impreciso, mas essa situação começa a mudar no sexto momento desta interlocução:

Questão: mesmo existindo ações sutis no mundo do desejo, não é possível extinguir aí as paixões. Isso acontece porque ele é o mundo da dispersão e da confusão. Não é possível esta extinção em uma mente dispersa e confusa. Conforme é ensinado nos Sutras, é preciso direcionar a mente no caminho e a mente dispersa e confusa não pertence ao caminho.

Resposta: É preciso elucidar as razões disto. Por que razão o mundo do desejo é chamado de mundo da dispersão e da confusão? Neste contexto existe a contemplação da impureza. Se ele consistisse realmente em um mundo da dispersão e da confusão, como seria possível contemplar aí as diferentes formas das ossadas? Ou ainda, se existem características distintas no controle da mente no mundo da forma, por que elas não poderiam existir no mundo do desejo? (TAISHOZÔ, 1924, p. 367-B).

O diálogo acima inicia a explicitação concreta da questão em pauta. O interlocutor aponta para o caráter essencial da dispersão mental e da confusão no mundo do desejo para fundamentar a impossibilidade de uma realização definitiva dentro de seus limites. Ou seja, como só em uma absorção no mundo da forma seria possível superar essa dispersão mental e 
essa confusão, a realização desta absorção seria um fator indispensável ao caminho. $\mathrm{Na}$ réplica do autor, está explícita a existência de um grau mínimo de estabilidade mental no mundo do desejo que é capaz de possibilitar a entrada no caminho. Ele conclui sua interlocução questionando as razões por que essas características da estabilidade e da clareza estariam presentes no mundo do desejo. O sétimo momento desta interlocução é bastante breve e sucinto: "Questão: é possível se afastar do desejo nos caminhos do mundo da forma. Este intervalo entre a morte e o renascimento no mundo da forma proporciona uma saída. Resposta: em que sentido isso é chamado de afastamento do desejo?” (TAISHOZÔ, 1924, p. 367-B).

Em um claro contraste com a interlocução acima, o oitavo momento deste diálogo é bastante longo e detalhado:

Questão: a extinção das paixões é chamada de afastamento do desejo. É através do caminho do mundo da forma e não do mundo do desejo que é possível extinguir as paixões.

Resposta: os diversos ensinamentos externos extinguem as paixões e voltam a renascer no mundo do desejo. Em função disto, o ignorante não realiza a extinção das paixões. Caso ele as extinguisse e ainda voltasse a nascer, isso seria equivalente a dizer que mesmo que o incontaminado possa extinguir as paixões, ele ainda está sujeito ao renascimento. Isto é impossível. Ou ainda, é ensinado nos Sutras que tendo extinguido as três paixões já estão extintos os três venenos. Como o ignorante não pode eliminar as três paixões ele não pode realizar o afastamento do desejo. $\mathrm{Ou}$ ainda, o ignorante possui permanentemente a mente que concebe o ãtman. Em função disto, ele não pode eliminar fatores como a visão do corpo. Caso o ignorante não consiga realizar o afastamento do desejo, todas as paixões perdem a sua consistência. Por que razão? Porque todas as paixões surgem através de condições. Conforme é ensinado nos Sutras, o conceito de ãtman surge de diversas condições. Caso este ignorante não faça surgir a visão do corpo através dos cinco agregados do mundo do desejo, isso também não acontecerá nos mundos superiores. Assim sendo, caso não exista a visão do corpo como pode existir essa falha? Estas paixões já deveriam estar eternamente extintas. Este ignorante já deveria ter se tornado um Arahat. Caso ele não realize verdadeiramente a extinção de todas as paixões. Conforme é ensinado nos Sutras, existem duas pessoas que não se assustam ao ouvir o ruído de um trovão. Elas são o Soberano da Roda da Lei e o Arahat. Agora, este também não deve ter esse temor. Ou ainda, o Arahat não deseja o nascimento nem encara a morte como um mal. É como o ArahatUpasena cujas raízes não apresentaram diferença de expressão facial e as cores de sua face não mudaram ao terminar sua existência picado por uma cobra. Esta pessoa também é assim. Ou ainda, a mente de um Arahatnão é perturbada pelos oito dharmas mundanos. Esta pessoa também é assim. Como ela se afasta do desejo, na verdade o ignorante pretender ter se afastado do desejo, mas não são todos que possuem esta característica. Em função disto, ele não extinguiu as paixões (TAISHOZÔ, 1924, p. 367-B, C). 
O diálogo acima é extremamente complexo e envolve diversos conceitos complicados relacionados à prática budista, mas seu conteúdo pode ser resumido da seguinte maneira: o interlocutor defende que a extinção das paixões não pode se dar no mundo do desejo, sendo necessária a experiência de alguma das absorções do mundo da forma. Em relação a isto, o autor apresenta uma réplica rigorosamente verdadeira sob o ponto de vista budista. Ou seja, as absorções do mundo da forma podem ser perfeitamente realizadas pelos praticantes não budistas, mas esta realização não tem por si só o poder de eliminar as paixões. A razão disto também é perfeitamente clara: a raiz das paixões é a ignorância que concebe o conceito de ãtman. Enquanto essa ignorância não for superada nenhuma absorção meditativa nenhuma absorção meditativa terá o poder de superar as paixões.

Assim sendo, mesmo aquele praticante que superou este conceito através de uma via conceitual no mundo do desejo está bem mais próximo da realização do caminho supramundano do que qualquer praticante não budista que tenha realizado com perfeição as absorções do mundo da forma. A comparação deste praticante budista com o Soberano da Roda da Lei e com o Arahat é evidentemente exagerada, mas aponta na direção certa: nenhuma absorção meditativa no mundo da forma que não pressuponha a superação do conceito de ãtman pode ser efetiva na realização do caminho supramundano. É possível considerar que existe ai uma clara defesa da importância da superação do conceito de ãtman que se dá no mundo do desejo. O nono desenvolvimento deste diálogo também é bastante longo e complexo:

\begin{abstract}
Questão: o ignorante pode extinguir as paixões. Se ele eliminar as paixões no intervalo entre a morte e o renascimento no mundo da forma, como pode se dar este mesmo movimento? Ainda é ensinado nos Sutras que existem caminhos externos que eliminaram as paixões. Ou ainda se ensina que Arãda-Kalãma nasceram no mundo do informe abandonando os mundos do desejo e da forma. Ou ainda se ensina que é possível afastar-se do desejo em função do informe. Que em função da extinção é possível romper com o surgimento dos pensamentos. Em função disto, você pode dizer que mesmo que o ignorante elimine as paixões ele ainda está sujeito ao renascimento e que isto não pode ser chamado de extinção, mas essa asserção é falsa. Você ainda afirma que as extinções dos ignorantes são superficiais, ou ainda que essas extinções implicariam apenas em um distanciamento. A verdade você ensina que a não extinção é uma extinção. Ou ainda é ensinado nos Versos, mesmo existindo o pensamento do ãtmane da propriedade do ãtman pode ocorrer a extinção com a morte. É como uma criança que brinca com paixão com seu brinquedo de areia, mas que o abandona quando ele se desfaz. Isso também pode ser considerado como uma forma de separação em relação ao desejo. No caso dos caminhos externos ocorre algo diferente de uma extinção através da morte, pois não é possível renascer
\end{abstract}


nos mundos da forma e do informe através da extinção que ocorre com a morte. Mesmo que uma criança pequena cultue o brinquedo de areia depois de abandonalo, não existe ai uma retribuição cármica. Mesmo que se trate da mesma palavra, seu sentido é completamente diferente. Em função disto podemos saber que ocorre verdadeiramente a extinção e a desconexão no ignorante.

Resposta: existem distinções entre os obstáculos. Se o obstáculo das paixões for profundo pode ocorrer o renascimento nos mundos da forma e do informe. Ou ainda, caso se trate do obstáculo da visão do corpo, esse equívoco já foi mencionado anteriormente. Caso não se trate de um obstáculo associado à visão do corpo em meio ao mundo do desejo, como poderia ocorrer o renascimento nos mundos da forma e do informe? É apenas quando os obstáculos são a cobiça e o ódio que se torna possível renascer no mundo da forma. Neste caso, a visão do corpo não se constitui como um obstáculo. Podemos saber em função disto que o ignorante não pode extinguir verdadeiramente as paixões. Ou ainda, existem dharmas benéficos no mundo do desejo que se constituem como um obstáculo às paixões. Ou ainda, podemos saber em função disto que existe a sabedoria do cultivo no mundo do desejo. Ou ainda se afirma nos Sutras que é possível realizar o caminho através da eliminação dos obstáculos. Podemos saber em função disto que pode existir a verdadeira sabedoria no mundo do desejo (TAISHOZỐ, 1924, p. 367-C).

Como de costume, o diálogo acima pode ser bastante longo e complexo, mas suas questões fundamentais podem ser resumidas de uma forma bastante simples. A totalidade das asserções do interlocutor parece enfatizar a centralidade dos mundos da forma e do informe de uma maneira completamente centrada na dimensão mundana da prática sem sequer se referir à questão da passagem do mundano para o supramundano. Em contraste com isso. $\mathrm{O}$ autor se refere à presença de dharmas benéficos no mundo do desejo e da capacidade da absorção no mundo do desejo de realizar a verdadeira sabedoria. No entanto, todas essas asserções do autor apontam para uma única questão: a possibilidade da realização supramundana dentro dos limites do mundo do desejo. Certamente, esta é uma tese ousada em meio ao pensamento budista, tese esta que é reiterada no décimo momento deste diálogo:

Questão: esta pessoa realizou o caminho do Arahat através de uma região próxima à primeira absorção. Isso não se deu em função de uma absorção no mundo do desejo. Resposta: não é desta forma. Quando nos referimos à eliminação dos sete obstáculos isso exclui tanto a primeira absorção quanto uma região próxima a ela. Ou ainda, as causas e condições presentes em uma absorção no mundo do desejo não estão associadas a esta região próxima. Se um praticante adentrar nesta região próxima, por que razão ele não poderia penetrar na primeira absorção. Não existem causas e condições que apontem para isto. Ou ainda se afirma no Sutra, ocorre primeiro a sabedoria da permanência no dharma e depois a sabedoria do Nirvana. Não precisa ocorrer em primeiro lugar a realização da absorção meditativa para que ocorra em seguida a extinção das paixões. Existe apenas a necessidade de se estabelecer primeiro na sabedoria da permanência no dharma, decorrendo daí naturalmente a posterior extinção das impurezas. Em função disto, se excluem as absorções meditativas. Como essas absorções são excluídas, assim é ensinado nos Sutras. Caso 
seja reconhecida esta região próxima, este equívoco passa a ser aplicado às absorções. Ou ainda, não existe referência nos Sutras a esta região próxima. Este discernimento deriva apenas de sua memória e de sua reflexão (TAISHOZÔ, 1924, p. 367-C, 368-A).

O diálogo acima é extremamente interessante e completamente atípico no contexto da literatura budista. Neste caso, o interlocutor aponta para a realização da condição de Arahat através de uma absorção que ocorre em uma região próxima à da primeira absorção no mundo da forma. Sua intenção é perfeitamente clara: negar a possibilidade de uma realização que se dê a partir de uma absorção no mundo do desejo conforme defendida pelo autor. A réplica do autor também é profundamente interessante. Em primeiro lugar, ele nega a existência desta região próxima à primeira absorção no mundo da forma a partir da autoridade textual dos Sutras. Esse movimento de pensamento a defesa da realização no mundo do desejo, mas ele dá aqui mais um passo decisivo ao apontar para a sabedoria da permanência no dharma como a dimensão central desta realização no mundo do desejo. Ou seja, independentemente da possibilidade de uma absorção no mundo do desejo, a dimensão central da realização consistiria na presença da sabedoria da permanência no dharma no próprio mundo do desejo. Mesmo que o autor ainda não desenvolva essa asserção de uma forma explícita, está implícita aqui pelo menos a possibilidade de uma realização integral do caminho através do exercício da dimensão conceitual da prática dentro dos limites do mundo do desejo. Esta questão ainda é desenvolvida na décima primeira interlocução presente neste diálogo:

Questão: me referi anteriormente à metáfora da brincadeira com a areia. Em função disto podemos saber que é possível extinguir as paixões em um caminho através de uma região distinta. É como uma areia grosseira que desloca uma areia mais sutil. Desta forma é possível extinguir o mundo do desejo através dos caminhos do mundo da forma. Se o praticante extinguir o desejo e os dharmas maléficos e não benéficos ele pode adentrar posteriormente na primeira absorção meditativa. Em função disto podemos saber necessariamente que existe uma região próxima. $\mathrm{O}$ desejo é extinto através disto. Ou ainda se ensina que o desejo surge em função da forma. Se não existisse essa região próxima, de que maneira a forma poderia ser uma causa? $\mathrm{Ou}$ ainda se ensina nos Sutras que se o praticante realizar a pura alegria ele poderá abandonar o desejo impuro. É da mesma forma com que Nãnda abandonou seu desejo original em função do amor pelas deusas celestiais. Ou ainda, se ele não realizar o sabor da serenidade e da extinção na primeira absorção meditativa, as mentes não poderão surgir em meio aos cinco desejos. Em função disto podemos saber que é possível abandonar o mundo do desejo realizando uma região próxima à primeira absorção meditativa.

Resposta: é possível eliminar os fatores maléficos através da realização do puro bem no mundo do desejo. É como falar a respeito da natureza das cinco saídas. Se os Sábios discípulos não deixarem surgir a alegria através da consideração sobre os 
cinco desejos sua mente se estenderá consumando esta direção. Caso eles mantenham sua atenção focada no dharma da saída sua mente realizará esta extensão. Ou ainda se afirma que se o praticante em função de ter suscitado o direcionamento para o objeto e a consideração de seu conteúdo em sua vertente não benéfica, ele poderá realizar a extinção através dos benefícios deste direcionamento para o objeto e da consideração de seu conteúdo. Em função disto, a metáfora da brincadeira com a areia também pode se concretizar no mundo do desejo. Sua posição de que é possível o afastamento do desejo através da forma não é algo que se dê posteriormente. $\mathrm{O}$ praticante pode extinguir as paixões através do caminho do mundo do desejo. Através desta extinção gradual ele pode realizar os dharmas benéficos do mundo da forma. Neste momento o mundo do desejo é chamado de desconexão suprema. Ao realizar o dharma do mundo da forma, é possível dizer que o Arahat realiza a absorção da extinção e que isso é chamado de realização das diversas absorções. É apenas quando você se refere ao sabor que você fala do sabor da alegria prodigiosa e da sabedoria do sabor da extinção. Todas essas questões já foram devidamente respondidas. Ou ainda, caso não existissem as absorções no mundo do desejo, como seria possível realizar o bem do mundo da forma através de uma mente dispersa? (TAISHOZÔ, 1924, p. 368-A).

O diálogo acima parece uma reiteração das teses anteriores, mas o décimo segundo e último momento deste diálogo aponta para uma conclusão inusitada para este debate:

Questão: no Arahat que se emancipa através da sabedoria é possível dizer que ele não possui as absorções e que ele só possui a sabedoria?

Resposta: neste contexto, precisa existir certamente um treino para as absorções que direcione a mente por um breve momento e a faça realizar o foco. Conforme é ensinado nos Sutras, é como quando o Buddhadiz aos Bhikkus que no momento em que recebem o Manto da ordenação ainda existem os três venenos, mas que no momento em que eles envergam o Manto eles são extintos. Não existe nenhuma passagem nos Sutras que reconheça que a verdadeira sabedoria pode surgir em uma mente dispersa. A mente é abarcada em todos os casos fazendo surgir a verdadeira sabedoria (TAISHOZÔ, 1924, p. 368-A,B).

O trecho acima resume de uma forma conclusiva a totalidade deste debate. O interlocutor pergunta se é verdade que em um Arahat que se emancipa através da sabedoria existe apenas a sabedoria e não as absorções meditativas. Essa é uma questão importante, pois caso a resposta seja afirmativa se torna plenamente reconhecida a possibilidade de uma completa realização do caminho supramundano através da dimensão conceitual da prática dentro dos limites do mundo do desejo. Certamente, o autor responde afirmativamente com uma única ressalva: como a verdadeira sabedoria não pode surgir em uma mente dispersa, é possível uma realização no mundo do desejo em que um grau mínimo de concentração torne possível o surgimento da verdadeira sabedoria. 
É possível concluir assim que o Satya-siddhi-Sãstra reconhece plenamente a realização do caminho supramundano através de um recurso exclusivo à dimensão conceitual da prática dentro dos estreitos limites do mundo do desejo. Na medida em que até mesmo a realização da condição de Arahat é reconhecida dentro desses limites, torna-se perfeitamente claro que se reconhece a passagem dos "Supremos dharmas mundanos" para a entrada no caminho da visão no mundo do desejo. Neste sentido, o ponto de vista do Satya-siddhi-Sãstra difere radicalmente do ponto de vista ortodoxo da escola Sarvãstivãda conforme representado pelo Jnana-Prasthãna. Existe mais uma possível conclusão a respeito das considerações acima. Caso a relação entre as três sabedorias conforme entendida no Satya-siddhi-Sãstra seja realmente defensável, podemos levantar a hipótese de que a sabedoria do cultivo não tenha uma relação necessária com a prática meditativa. Ou seja, decorre dai um caminha para compreendê-la como um desdobramento concreto das sabedorias do ouvir e da reflexão que representam a dimensão conceitual da prática budista. Certamente este tema pode merecer um tratamento especial em alguma publicação futura.

\section{Conclusão}

O percurso de pensamento presente neste trabalho, assim como suas possíveis consequências pode ser resumido através dos três pontos seguintes:

a) A relação entre as dimensões conceituais e não conceituais da prática budista apresenta três modalidades. O primeiro caso seria uma modalidade de prática completamente centrada na dimensão não conceitual e instrumentalizada através de um treinamento intenso nas diversas modalidades da absorção meditativa. Neste caso, a prática da absorção ocorreria sem a presença de um pano de fundo conceitual representado pelas sabedorias do ouvir e da reflexão. Como esta possibilidade não possui fundamento algum na literatura do Abhidharma das escolas Sarvãstivãda e Sautrântica ela não pode ser reconhecida dentro da referência proporcionada pelo referencial de uma tradição budista entendida de forma rigorosa. $\mathrm{O}$ segundo seria a alternativa representada pela ortodoxia da escola Sarvãstivãda. Ou seja, uma modalidade de prática que estabelece uma forte conexão entre as dimensões conceituais e não conceituais da prática budista. Esta alternativa se expressa através da passagem dos "Supremos dharmas mundanos" para o caminho da visão no mundo da forma e pressupõe 
uma conjunção entre as sabedorias do ouvir e da reflexão como expressões da dimensão conceitual da prática e a entrada em pelo menos a primeira absorção meditativa no mundo da forma. Esta modalidade de compreensão possui um caráter hegemônico em meio às principais tradições budistas. O terceiro e último conforme representado pelo Capitulo sobre as três sabedorias no Satya-siddhi-Sãstra implica em uma quase completa independência da dimensão conceitual do caminho. Caso seja levada adiante a compreensão das três sabedorias conforme presente neste capítulo, a totalidade do caminho pode ser realizado de forma perfeita através da dimensão conceitual e dentro dos limites estritos do mundo do desejo. Como até mesmo a realização da condição de Arhat pode se dar em meio a estes limites, a conclusão necessária é que o Satya-siddhi-Sãstra admite claramente a possibilidade da passagem dos "Supremos dharmas mundanos" para o caminho da visão através de uma via essencialmente conceitual que se efetue dentro dos limites do mundo do desejo. Esta modalidade de compreensão é extremamente atípica em meio às tendências dominantes da tradição budista, mas é uma hipótese com profundas implicações e que merece ser levada a sério.

b) Se um possível diálogo entre o Budismo e a filosofia ocidental for relacionado com as três alternativas acima descritas, talvez nos seja possível apontar para as seguintes conclusões. Se a prática budista for entendida apenas em função da primeira alternativa, ou seja, de uma compreensão exclusivamente centrada nas dimensões não conceituais conforme expressas nas absorções meditativas o diálogo entre o Budismo e a filosofia ocidental perde completamente o seu sentido. Pode acontecer de indivíduos que exercem a atividade filosófica se dedicarem a estas práticas, mas não poderá ocorrer nenhum diálogo entre essas duas tradições. Como esta possibilidade não possui respaldo algum na literatura normativa do Budismo, essa hipótese pode ser completamente desconsiderada. Caso a mesma questão venha a ser colocada em termos da segunda alternativa, é possível afirmar em princípio que nada impede um diálogo entre essa modalidade de compreensão e a tradição da filosofia ocidental, mas talvez faça sentido interrogar a respeito de um possível vínculo entre a investigação filosófica em estilo ocidental e a prática das diversas absorções meditativas. Caso esta hipótese venha a ser reconhecida como significativa pelos estudiosos da filosofia ocidental ela talvez possua o potencial de abrir novos caminhos no diálogo entre a filosofia ocidental e o Budismo. Por fim, a posição apresentada pelo Capítulo sobre as três sabedorias no Satya-siddhi-Sãstra talvez 
venha a possuir um sentido incomum no contexto deste diálogo. Ou seja, caso a plenitude do caminho budista possa ser realizada através do exercício exclusivo da dimensão conceitual da prática dentro dos limites do mundo do desejo, isso pode apontar para um pleno potencial da filosofia como um caminho de auto transformação e de realização espiritual. Embora as filosofias do Helenismo e da Antiguidade tardia como o estoicismo, o epicurismo e o Neoplatonismo recorressem a práticas espirituais que apresentam semelhanças com a prática das absorções meditativas no Budismo, talvez essas mesmas filosofias possam vir a ser repensadas em sua relação com a compreensão da prática no Satya-siddhi-Sãstra.

c) A questão de um possível diálogo do pensamento budista com as aplicações terapêuticas ou com os estudos científicos da prática da meditação é de longe a questão mais complexa no contexto do presente artigo. Na medida em que os discursos do Budismo e das diversas ciências partem de pressupostos e de preocupações bastante distintos, a questão central neste contexto consistiria em definir o terreno comum a partir do qual este diálogo posse se desenvolver. É completamente pueril esperar que as ciências "comprovem" as teses do pensamento budista ou que a compreensão budista da mente e das funções mentais venha pura e simplesmente "corroborar" os resultados das diversas ciências. Neste sentido, a questão central consistiria em elucidar o terreno comum que possibilitaria o diálogo entre essas formações epistêmicas de natureza bastante diversa. Caso este problema seja situado em sua relação com as três modalidades de compreensão da prática acima elencadas, talvez seja possível dizer o seguinte: no caso de uma compreensão da prática completamente centrada na dimensão não conceitual e nas absorções meditativas, não seria nem mesmo possível colocar o problema do diálogo entre o Budismo e as ciências. O único procedimento cabível neste caso seria um estudo das implicações psicológicas, neurofisiológicas e outras destas práticas.

No caso da compreensão presente na ortodoxia da escola Sarvãstivãda talvez se torne possível um diálogo propriamente dito entre o Budismo e as ciências, mas seria necessário um grande esforço no sentido de elucidar os pressupostos deste diálogo. Por fim, a compreensão da prática conforme presente no Capitulo sobre as três sabedorias no Satya-siddhi-Sãstra poderia fornecer um forte contraponto crítico às apropriações ingênuas das práticas budistas pelos diversos procedimentos científicos, mas dificilmente poderia proporcionar um térreo comum para um diálogo significativo entre o Budismo e as diversas ciências e práticas de 
inspiração científica. Neste sentido, todo esse debate ainda parece estar à espera de uma formulação mais precisa e mais rigorosa de suas premissas e de seus pressupostos.

\title{
Referências
}

JUNJIRÔ, T.; KAIGYOKU, W. (Ed.). Taishozô (TaishôTripitaka, TaishôShinshuDaizôkyô). Tokyo: TaishôIssaikyoKankokai, 1924-1934a. v. 26.

JUNJIRÔ, T.; KAIGYOKU, W. (Ed.). Taishozô (TaishôTripitaka, TaishôShinshuDaizôkyô). Tokyo: TaishôIssaikyoKankokai, 1924-1934b. v. 29.

JUNJIRÔ, T.; KAIGYOKU, W. (Ed.). Taishozô (TaishôTripitaka, TaishôShinshuDaizôkyô).Tokyo: TaishôIssaikyoKankokai, 1924-1934c. v. 32.

\section{THE CONCEPTUAL AND NON-CONCEPTUAL DIMENSIONS OF BUDDHIST PRACTICE- CENTERED IN THE CHAPTER ON THE THREE WISDOMS IN THE SATYA-SIDDHI-SÃSTRA.}

\begin{abstract}
The present work is completely grounded in the methodology of textual analysis as present in buddhist studies and has three essential pretentions. The first one is to discuss the relationship between the conceptual and non-conceptual dimensions of buddhist practice from the standpoint of the concept of the three wisdoms. The second one is to define a central standpoint able to judge the difference between buddhist practice proper and the therapeutic and scientific approaches to meditation. The third one tries to think the complete autonomy of the conceptual dimension from an analysis of the relationship between the three wisdoms and the three worlds in the Satya-siddhi-Sãstra.
\end{abstract}

Keywords: conceptual and non-conceptual dimensions of buddhist practice; three wisdoms; three worlds; meditative absorption; Satya-siddhi-Sãstra. 